\title{
Investigating Health and Safety in Science Laboratories in Saudi Arabian Secondary Schools
}

\author{
Saad Alshehri \\ University Of Jeddah
}

\begin{abstract}
This paper presents the findings of a study that investigated teachers' perceptions of health and safety risks in science laboratories in secondary schools in Saudi Arabia. It identified the level of knowledge of school staff about health and safety risks and reviewed the current practices in the schools. A mixed methods study design was utilised to investigate the phenomenon. A stratified random sampling technique was used to select male and female teachers from 19 secondary schools in two cities, Jeddah and Riyadh. The survey was developed by adapting items from previous studies. Descriptive statistics and independent t-Test analyses were used to analyse the survey data and present the results. Interview questions, developed from literature, were used to collect qualitative in-depth data and complement quantitative data. The qualitative data was thematically analysed.
\end{abstract}

Quantitative results revealed that there were very few differences in the perceptions of teachers based on gender. When interviewed, most teachers reported they had no knowledge of prudent work practices, lacked training and were not supported by school management and policy makers. Overall the findings indicate that the safety culture in the school laboratories was less well established. The results of this study can have important implications for both school stakeholders responsible for implementing health and safety in school laboratories and the policy makers.

The empirical contribution of this paper is founded on the fact that this study is conducted in the context of health and safety risks in science laboratories at secondary school level where there is limited empirical evidence. The adoption of a holistic mixed methods investigation yielded findings which contributed to a better understanding of issues in laboratories and how schools and policymakers can carefully consider practices that support a positive safety culture.

Keywords: Health and safety risks, Culture of safety, Safety climate, School laboratories 


\section{Introduction}

Health and safety in school laboratories are indispensable elements which are essential for the teaching and learning process (Högström, Ottander, and Benckert 2010; Miliszewska and Sztendur 2011). Laboratories contain dangerous hazardous materials or chemicals, radioactive substances, and flammable objects and are therefore dangerous workplaces. These unsafe substances can have negative impacts on students', teachers' and laboratory personnel's health and the school environment (Ijaz and Malik 2018). Nevertheless, laboratory safety is not given inordinate importance due to the assumption that a small quantity of chemicals or substances would not be hazardous (Langerman 2009). On the other hand, risks of laboratory accidents in schools and colleges are far greater than in commercial establishments or plants (Ismail, Kadir, and Aiyub 2015). It is claimed that in order to create a safety culture in educational institutions and change attitudes and behaviours, utmost attention has to be given to leadership, educating individuals on safety and health through training, promoting good safety attitudes, and documenting safety incidents so that lessons can be learnt from past experience (Finster 2017). Good signage and posters can complement training and act as persistent reminders (National Research Council 2011).

In school laboratories, especially in a centralised education system such as in Saudi Arabia, it is the responsibility of the policymakers to ensure that all teachers and laboratory personnel are trained on health and safety issues (Alsubaie 2017), especially to manage emergencies, when handling and storing substances during experiments, disposing waste and using a fire extinguisher in case a fire caused by inflammables (National Research Council 2011). In addition, skills in administering first aid is critical in reducing the effects of accidents and hazards. According to schedule 2 of the Occupational Safety and Health Regulation every school should have at least 2 trained teachers for administering first aid in the event of emergencies and accidents (Education Bureau 2013). It is claimed that safety in laboratory settings is the responsibility of all concerned (Anza, Bibisio, Kuma, and Osuman 2016). Research suggests that mishaps and risks can be mitigated or prevented if there is collective responsibility, or if there is full cooperation of everyone in a laboratory (Finster 2017; Bahram, Maryam, and Fatemeh 2013) for instance teachers, laboratory technicians, other staff and students.

\section{Research problem and rationale}

A critical component in health and safety risk management is to identify hazards and mitigate its associated risk using adequate training programmes for teachers and laboratory personnel. Unfortunately, research from Saudi Arabia indicate that health and safety risks are only associated with road traffic accidents and hospitals (Alsubiaee et al. 2017), which suggests that the focus is not on fostering safe educational environments. 
The level of awareness among school staff in Saudi Arabian schools is low and few are aware about safety needs, but many are ill prepared (Alsubie et al. 2017). Most schools are not in compliance with regulations for emergency preparedness and school staff lack training (Alsubaie 2017). Under such circumstances, it is not known if teachers, students and those working in laboratories are aware of the many dangers associated with hazardous chemicals and substances. Although, it is common that safety symbols and signs are posted in laboratories to maintain a safe environment and avoid accidents, staff, and students should also be able to understand the hazard communication information on the laboratory safety signs (Adane and Abeje 2012).

Empirical evidence on teachers' perception on health and safety risks in school laboratories is scarce. One study that examined agricultural mechanics teachers' perceptions of safety practices New Mexico, USA, found that posters and safety inspections were given least importance, that instructors were least prepared and relied on their past experiences and personal beliefs to handle safety issues or teach students how to mitigate risks (Chumbley 2015). Alyammahi (2015) examined the status of safety practices of Chemistry teachers in American high schools. The study surveyed the teachers and found that several classrooms did not meet the safety laws as the teachers were not familiar with the regulations. As a result, there was a relatively high incidence of hazards and accidents in the laboratories.

There exists a gap between evidence-based interventions to ensure safe and nurturing environments for young people in school labs and practice. Some of the crucial aspects that contribute to this problem include lack of research, lack of public awareness, and poor support from policy makers (Mallonee, Fowler, and Istre 2006). Therefore, the purpose of this study is to investigate teachers' perceptions of health and safety issues in school laboratories and if schools have been able to successfully implement school health and safety standards. The study focuses on the following three questions:

1. What are teachers' perceptions of the prevalence and frequency of risks and hazards caused by unsafe practices in their school laboratories?

2. To what extent do male and female teachers differ in their perceptions of safety in school laboratories?

3. How do teachers perceive the factors that impede schools from implementing health and safety standards in school laboratories?

\section{Objectives}

The main aim of the study is to acquire data by investigating teachers' perceptions of current practices in health and safety in these laboratories by understanding their experiences of risks, consistency of school safety norms for labs, and whether there is a 


\section{EDUCATION}

positive safety climate or a negative safety climate. It investigates if gender would help explain the differences in teachers' perceptions of safety in school laboratories. Finally, it examines the barriers encountered by schools and teachers when implementing and managing health and safety risks in science laboratories.

\section{Research design and methods}

This study used both quantitative and qualitative approaches to provide a more complete understanding of the research problem. A pragmatic philosophical perspective and worldview was used in this study to examine multiple perspectives of the research participants. The objective was to gain 'participants' views of the situation being studied' (Creswell, 2013, 8). Another reason for using a pragmatic approach was that it is claimed to be a paradigm for educational research concerned with the application of research to practice (Taatila and Raij 2012; Morgan 2014). The approach was inductive which is concerned with the generation of new theory emerging from the data, thereby enabling the researcher to explain what is taking place (Saunders, Lewis, and Thornhill 2009).

\section{Sample}

The target population for this study included nineteen secondary schools chosen from the 2 largest cities in Saudi Arabia, Jeddah and Riyadh

Table 1 Demographic composition of schools

School parameters

Number of schools

School size

$$
800 \text { to } 1000 \text { students }
$$

Schools with science laboratories

Schools with laboratory technicians
900 to 1200 students

Secondary schools in Jeddah

Secondary schools in Riyadh 


\section{EDUCATION}

The schools were purposively selected to participate in the study since they had laboratories. These were government-run schools that received adequate funding from the Ministry of Education and were in various stages of implementation of safety policies.

Table 2 Sampling frame

\begin{tabular}{lcc}
\hline Research instruments & $\begin{array}{c}\text { Participants from } \\
\text { schools in Jeddah }\end{array}$ & $\begin{array}{c}\text { Participants from } \\
\text { schools in Riyadh }\end{array}$ \\
\hline Questionnaires & 74 teachers (Male 41; & 73 teachers (Male 34; \\
Fnterviews & Female 33) & Female 39) \\
& 6 teachers (Male 3; & 6 teachers (Male 3; \\
& Female 3) & Female 3) \\
\hline
\end{tabular}

For the questionnaire, a sample of 147 participants was selected (see Table 2). A stratified random sampling method was used to select the male and female teachers from a target population of 1452 participants located in Riyadh and Jeddah. Initially a sample of 252 postgraduate teachers, comprising of male and female teachers, was selected from the 19 schools which had laboratories. A total of 147 completed the questionnaires. For the interviews, 12 participants were selected using purposeful convenience sampling technique (see Table 2) based on the recommendations of Creswell (2013) and Mason (2010) who claim that for qualitative research the sample size can be anywhere between 10 and 40.

\section{Data collection methods}

For this study, a mixed methods design was needed because just using one data source, in the form of questionnaires, was considered insufficient, since sociological perspectives of participants on social problems cannot always be measured numerically (Silverman 2006). Therefore, interview data was also collected.

A questionnaire survey was developed by adapting items from literature. The questionnaire gathered information on the teachers' perceptions of safety in school science laboratories. The variables chosen for this study were supported by previous literature that examined safety in school labs (for example Ijaz and Malik 2018; Alsubaie 2017; Finster 2017; Anza et al. 2016; Adane and Abeje 2012; Wamuziri 2011; Mallonee et al. 2006) and teachers' perceptions of safety in such environments (Alyammahi 2015; Chumbley 2015).

The dependent variable in this study is 'safety' in science laboratories, a composite variable which encompasses the prevalence and frequency of risks and hazards caused by 
unsafe practices in their school laboratories (items 1 to 4 of Section II of the questionnaire). The independent variables are the teachers' perceptions of the 'consistency of safety norms', and 'safety climate' in school laboratories. These independent variables are composite variables which were created by combining two or more individual variables. The variable 'consistency of safety norms' includes the constructs adequate staff training, support of policy makers, clear and understandable posters and operating procedures, and consistency of application of rules. The variable 'safety climate' represents the perceived value placed on safety in schools and laboratories by teachers and consists of teachers' awareness of chemical symbols and signs, awareness of proper chemical storage practices, capability to respond quickly to emergencies, perceived value of safety and importance of the school laboratory as well as commitment to ensure student safety. All items were accompanied by a 4-point Likerttype response scale. Cronbach's alpha was applied to validate or measure the internal consistency or reliability of questionnaire items. The reliability coefficient for all 14 items is 0.713. It is recommended (Streiner and Norman 2008) that alpha value is greater than 0.7 is indicative of a respectable level of reliability.

The interview schedule was developed by reviewing literature (Alsubie et al. 2017; Alyammahi 2015; Chumbley 2015; National Research Council 2011; Lavack et al. 2008; Mallonee et al. 2006) and to suit the research requirements. The interview schedule was designed to gather information about participants' understanding of health and safety risks, their responsibilities, their experiences in the laboratory, health and safety training, their perceptions and understanding of guidelines and current practices, their perceptions of the challenges facing schools in implementing safety programmes and the role of the policymakers in supporting and ensuring safety.

\section{Procedures}

Ethical approval was obtained from the relevant university research ethics committee before embarking on this study. Participants were provided a thorough description of the research process and they were duly informed that anonymity, confidentiality, and privacy would be honoured and maintained.

Printed questionnaires were handed over to the head teachers or principals of the 19 schools who were requested to distribute the surveys to 252 teachers. On completion of the questionnaires, the teachers were asked to return the completed forms to the head teachers. Follow up phone calls were also made, and the head teachers ensured that the participants would respond within two weeks. The return rate was $58.3 \%$ as 147 of the 252 teachers returned the completed questionnaires.

Participants were interviewed in a mutually selected location within the schools (for instance in a study room at the library or in the staff room), which were quiet and comfortable environments where the participants were at ease. In spite of a prepared interview schedule, probes were also used to gain a thorough understanding of the responses and obtain in-depth information. Participants' responses were recorded using 


\section{EDUCATION}

an audio-recording equipment (Sony V16 audio recorder). Anonymity and confidentiality were maintained by allocating ID numbers to the school staff (for example teachers were identified as T1, T2.) and such information was noted in a diary in a sequence to match with the recordings. The audio recording enabled the researcher to directly quote the narratives, maintain a level of accuracy, and to review the responses during transcription (Driscoll 2011). This ensured the validity of the data.

\section{Data analysis}

Demographic data (gender, qualifications and school location) were summarized using descriptive statistics. All teachers were postgraduates. Gender-related information was essential to determine its impact on the findings of the study. Descriptive statistics (frequencies) were used to present the results of the survey responses. Independent t-Test analyses were performed to determine if teachers' gender can explain the differences in their perceptions of safety in school laboratories.

Qualitative data was collected and analysed thematically to determine the possible influential factors that impede schools from implementing health and safety standards in the science laboratories. The analysis involved six stages which included familiarisation with the data by reading it several times, coding the data, looking for clear and meaningful patterns in the coded data, reviewing the themes, defining and naming the themes and finally writing the narrative (Braun and Clarke 2006).

Methodological triangulation was used to mix the information from questionnaires and interviews to produce convergent findings. This approach was adopted as it is considered to be useful in providing confirmation of findings, for enhancing validity and better understanding of the research problem (Bekhet and Zauszniewski 2012).

\section{Results}

Findings are presented according to the research questions for the study. To answer research question 1, descriptive statistics (Table 3) was applied.

Table 3 Means of teachers' $(\mathrm{N}=147)$ perceptions of safety in school laboratories

\begin{tabular}{clcc} 
& \multicolumn{1}{c}{ Items } & Mean & SD \\
\hline 1 & During the past 2 months how safe have you felt at school? & 1.71 & 0.45 \\
2 & Where do you feel most unsafe at school? & 1.44 & 0.88 \\
3 & $\begin{array}{l}\text { During the last one month, how many days did you feel that } \\
\text { you/students were unsafe in the lab }\end{array}$ & 2.54 & 0.78 \\
4 & How often does injuries or mishaps take place? & 2.55 & 0.79 \\
5 & All staff are trained to ensure lab safety & 1.61 & 0.49
\end{tabular}




\section{EDUCATION}

6 Policymakers monitor school laboratories and contribute to positive health and safety cultures in schools

7 There are posters and written standard operating procedures for preventing hazards, that are explicit and unambiguous

8 The rules are the same for all students and staff

9 Teachers are aware of all chemical symbols and signs

10 Teachers are aware of proper chemical storage practices

11 Teachers can quickly respond to emergencies

12 My school lab is safe

13 The school lab is important to me

14 I am committed to ensuring the safety of student when they use the lab

$* M=$ Mean $; S D=$ Standard Deviation

The prevalence and frequency of risks and hazards caused by unsafe lab practices was examined via items 1 to 4 . All male and female teachers reported that they felt unsafe or very unsafe in their schools (Table 4) and that laboratories were the most hazardous places in the schools (Table 5). Most teachers (Male N=55 and Female N=9) felt unsafe 4-5 days a month (Table 6), while a vast majority (Male $\mathrm{N}=54$ and Female $\mathrm{N}=9$ ) stated that injuries or mishaps occurred one or more times a month (Table 7).

Table 4 Frequencies for the question: During the past 2 months how safe have you felt at school?

$\begin{array}{lcc} & \text { Male } & \text { Female } \\ \text { Unsafe } & 55(37.4 \%) & 50(34 \%) \\ \text { Very } & 20(13.6 \%) & 22(15 \%) \\ \text { Unsafe } & \end{array}$




\section{EDUCATION}

Table 5 Frequencies for the question: Where do you feel most unsafe at school?

$\begin{array}{lcc} & \text { Male } & \text { Female } \\ \text { Lab } & 61(41.5 \%) & 56(38.1 \%) \\ \text { Gym } & 13(8.8 \%) & 13(8.8 \%) \\ \text { Cafeteria } & 1(0.7 \%) & 3(2 \%)\end{array}$

Table 6 Frequencies for the question: During the last one month, how many days did you feel that you/students were unsafe in the lab?

$\begin{array}{lcc} & \text { Male } & \text { Female } \\ 4-5 \text { days } & 55(37.4 \%) & 39(26.5 \%) \\ 2-3 \text { days } & 10(6.8 \%) & 17(11.6 \%) \\ 0-1 \text { days } & 10(6.8 \%) & 16(10.9 \%)\end{array}$

Table 7 Frequencies for the question: How often does injuries or mishaps take place?

Male Female

One or more times a month

$54(36.7 \%)$

$39(26.5 \%)$

One or more times a fortnight

$11(7.5 \%)$

$16(10.9 \%)$

One or more times a week

$10(6.8 \%)$

$17(11.6 \%)$

Items 5 to 8 focused on teachers' perceptions of consistency of safety norms and their responses ranged from (1) not true at all, (2) not true, (3) true, to (4) very true. Items 9 to 14 focused on teachers' perceptions of safety climate and their responses ranged from (1) 
really disagree, (2) disagree, (3) agree, to (4) really agree. The higher mean scores for the items 5 to 14 ranged from $M=2.2$ to $M=3.14$ on a scale of 1 to 4 (Table 3). However, it is not possible to make inferences from descriptive data.To answer research question 2 , independent t-Test analyses were conducted to determine whether gender explained teachers' perceptions of safety in the laboratories. The hypothesis for the 2 nd research question was stated as follows:

Ho: There are no differences in the perceptions of male and female teachers regarding safety in the school laboratories.

Table 8 Differences in perceptions regarding safety in school laboratories based on gender

\begin{tabular}{|c|c|c|c|c|c|}
\hline & \multirow{2}{*}{ Items } & \multicolumn{2}{|c|}{ Mean } & & \multirow{2}{*}{ sig } \\
\hline & & $\mathrm{M}$ & $\mathrm{F}$ & & \\
\hline 1 & $\begin{array}{l}\text { During the past } 2 \text { months how safe have you } \\
\text { felt at school? }\end{array}$ & 1.73 & 1.69 & 0.518 & 0.605 \\
\hline 2 & Where do you feel most unsafe at school? & 1.39 & 1.49 & -0.685 & 0.495 \\
\hline 3 & $\begin{array}{l}\text { During the last one month, how many days did } \\
\text { you feel that you/students were unsafe in the } \\
\text { lab? }\end{array}$ & 2.40 & 2.68 & -2.206 & 0.029 \\
\hline 4 & $\begin{array}{l}\text { How often does injuries or mishaps take } \\
\text { place? }\end{array}$ & 2.41 & 2.69 & -2.187 & 0.030 \\
\hline 5 & All staff are trained to ensure lab safety & 1.60 & 1.63 & -0.309 & 0.758 \\
\hline 6 & $\begin{array}{l}\text { Policymakers monitor school laboratories and } \\
\text { contribute to positive health and safety culture } \\
\text { in schools }\end{array}$ & 1.60 & 1.60 & 0.032 & 0.974 \\
\hline 7 & $\begin{array}{l}\text { There are posters and written standard } \\
\text { operating procedures for preventing hazards, } \\
\text { that are explicit and unambiguous }\end{array}$ & 2.39 & 2.01 & 2.644 & 0.009 \\
\hline 8 & $\begin{array}{l}\text { The rules are the same for all students and } \\
\text { staff }\end{array}$ & 1.97 & 1.89 & 0.815 & 0.416 \\
\hline 9 & $\begin{array}{l}\text { Teachers are aware of all chemical symbols } \\
\text { and signs }\end{array}$ & 1.92 & 1.85 & 0.691 & 0.491 \\
\hline 10 & $\begin{array}{l}\text { Teachers are aware of proper chemical storage } \\
\text { practices }\end{array}$ & 1.79 & 1.81 & -0.178 & 0.859 \\
\hline 11 & Teachers can quickly respond to emergencies & 1.64 & 1.60 & 0.531 & 0.597 \\
\hline 12 & My school lab is safe & 3.13 & 3.15 & -0.210 & 0.834 \\
\hline 13 & The school lab is important to me & 3.01 & 3.07 & -0.619 & 0.537 \\
\hline
\end{tabular}

14 I am committed to ensuring the safety of student when they use the lab

$\begin{array}{llll}3.05 & 3.04 & 0.120 & 0.905\end{array}$


The independent t-tests revealed (Table 8) there were no statistically significant differences between the participants' perspectives on eleven items (questions 1,2,5,6 and 8 to 14). Since the p-value of all these items were greater than the significance level ( $\mathrm{p}>$ $.05)$, there was not enough evidence to reject the null hypothesis. However, there were three items (questions 3,4 and 7) with significant differences in the perceptions of teachers. These included the frequency of the number of days teachers felt unsafe $(\mathrm{t}(141)$ $=-2.206, p=0.029)$, the occurrences of injuries or mishaps $(t(141)=-2.187, p=0.030)$ and the availability of clear posters and written guidelines for preventing hazards ( $\mathrm{t}(141)$ $=2.6444, \mathrm{p}=0.0091)$. Since the $\mathrm{p}$-value is lesser than the alpha $(\mathrm{p}<.05)$, the null hypothesis was rejected.

To answer research question 3, qualitative data from the interviews were analysed thematically which yielded four overarching themes:

\section{Lack of prudent practices}

The interview sessions provided opportunity for participants to reflect on current practices. The participants perceived that the lack of safety culture as well as clear information or guidelines had contributed to reckless practices in the laboratories. There were frequent comments signifying the possible limitations of the current practices of the school staff. For instance, a teacher claimed that:

'There is a lack of health and safety culture in science in laboratories. Some safety equipment such as fire extinguisher and gloves are available. However, this culture is not sustainable. Health and safety do not get high priority.' (T9)

The respondents made reference to a range of issues faced by schools in Saudi Arabia, for instance:

'There is no one responsible for health and safety of employees, students and others. Some schools nominate someone to just have a name on the record but not all schools have assigned an individual as a routine.' (T12)

'There are no laboratory technicians in this school.' (T3)

'Teachers manage laboratories and ensure that the right equipment, tools, chemicals and other materials are adequately stocked and kept in working condition. However, they do not know how to react in an emergency.' (T6)

The following comments show that there were no written standard operating procedures for preventing hazards: 
'There are no health and safety posters in schools.' (T4)

'There are no corrective measures and the procedures are vague for example, we do not know how to deal with chemical spills and how it may affect an individual.' (T5)

The above responses indicate that none of the practices centred on caring for the staff and students. All the interviewees seemed to agree that there was the need for incorporating better practices. The lack of safe procedures and the overconfidence or ignorance of some staff was also evident in the following remark:

'With regard to waste disposal we simply just pour the substance into the sink or throw it as normal garbage. I saw a technician pour the material in to the sand, which according to him was one way of getting rid of inflammables.' (T8)

Overall there was a general consensus on the need to better understand the reckless behaviour factors that affect safety.

Lack of safety training

The respondents were concerned that did not have health and safety training to prevent hazards or accidents. When participants' views were sought on in-service training, some teachers responded as follows:

'I guess laboratory technicians are provided training. Not teachers. The workshops we attended were few and far between. Moreover, the courses are short, useless and focus on theory.' (T3)

'Also, I would like to say that some teachers avoid using them because most of the materials had expired or because they have no proper training.' (T10)

'Safety training is not considered a vital component of the laboratory safety program within most schools.' (T11)

A majority of participants referred to gaining some theoretical knowledge but were unhappy with the training programmes.

'If we are to ensure health and safety in the laboratory, we need skills not theoretical knowledge. However, this is not a skill that comes naturally. We must be taught how to handle emergencies. We need training and ongoing support.' (T4)

'If teachers and laboratory personnel who handle chemicals are to perform their work in a careful manner they need adequate training to accurately identify and assess hazards in the laboratory.' (T7)

'Our training needs are often overlooked or ignored by the policy makers.'

From the aforementioned responses, it is apparent that the interviewees wanted more support from the Ministry of Education so that they can have much greater awareness of health and safety concepts, and proactively manage risk and avoid injuries. Adequate 
training was emphasised as contributing to the health and safety of students, teachers, and other staff.

\section{Reliance on general knowledge}

The research participants were not collecting safety information from relevant sources as there were no guidelines or supervisory bodies to provide resources and support. Instead they were making decisions based on general knowledge or using online information.

\section{'I learned how to avoid Inhalation of hazardous chemicals using Google.' (T4)}

'I was able to teach students how to avoid Ingestion of hazardous chemicals after reading articles online.' (T2)

'We had some instances of chemical spills and we acquired some kits on our own to clean the area. We also bought first-aid kits that were easily accessible whenever there were cases of injury in the laboratory.' (T12)

These responses indicate that the participants lacked access to relevant health and safety information, and that they were expected to learn about it on their own. The interviewees also reported that there was a lack of communication between policymakers and schools:

'There is no open communication between management and teachers to facilitate prompt report of and response to unsafe conditions. Also, no accident or incident records.' (T10)

As safety information was not continuously circulated and as the staff did not receive important updates, they were unable to improve safety culture within the schools.

\section{Inadequate policies}

In order to nurture a culture of safety and encourage active involvement of school staff, the management and policy makers have to be committed. They should allocate adequate resource, putting safety first, designate supervisors to monitor school safety, and respond appropriately in times of need. Opinion was sought on this and participants were asked to explain how this relates to their schools and laboratories. Many participants reported a significant mismatch between the policies and the support they received.

'I have more than 20 years experiences and some of the laboratories are safe and some are not. In fact, they raise safety levels only if something happens. Policymakers are not proactive. I will give you an example, when one of our schools in Jeddah caught fire and 
a number of female students died, the Department of Fire and Emergency Serveries increased visits to all schools but then it abruptly stopped.' (T5)

'The schools are responsible for creating a safe environment, but the Ministry of Education does not encourage a culture of safety.' (T7)

From the above response, it is apparent that the policymakers were not committed. Additional problems, such as lack of guidelines or benchmarking, hindered the effectiveness of good health and safety practices:

'There are no nationally agreed guidelines.' (T1)

'There is no benchmarking and we are not able to compare the health and safety processes and performance with international standards.' (T3)

'With regard to health and safety policies very few schools are competent enough to handle hazards. They lack safety information and standards. So, it is up to the schools with no pressure from outside.'

One female teacher highlighted that the policies were against women, reporting that they were less in control of the situation during emergency evacuation:

'As women we have an issue and it is difficult to evacuate schools immediately in case of a hazard or emergency. We are required to take permission as we are not allowed to go outside the schools without 'mahrem' or a relative such as father or brother or husband. For example, during a large and deadly fire in a girls' school more than 15 students died and 50 were injured, while in another incident 2 teachers were killed. Both incidents show how difficult it is to evacuate female students and staff in case of emergency.' (T8)

Teachers were of the view that the policymakers overlooked some of the important factors that contribute to positive health and safety cultures in schools.

'There is lack of adequate supervision. Supervisors nominated by the Ministry of Education visit schools only once a year. Also, they ignore our requirements.' (T6)

'The evaluation systems are not compliant with international norms. A safety program must be monitored and reviewed to make sure that the safety goals are met.' (T10)

These responses indicate that the participants were aware that the concept of health and safety culture must be evaluated. This also demonstrates that safety programmes have to be initiated from the top in schools. The responses also show that there is a link between top management commitment and school involvement in health and safety initiatives.

\section{Triangulation and integration of findings}

Overall, the findings from the quantitative phase indicate that there are very few differences in the perceptions of teachers based on gender. The data from the 
questionnaires suggest that respondents lacked knowledge of safety signs and failed to identify important safety signs. Thematic analysis of the interview data revealed that respondents did not have knowledge of safety signs due to lack of safety training. Qualitative results provided the rationale why school staff were unable to identify important safety signs. The richness and individuality of the school staffs' interview responses indicate that schools were not only unable to develop a culture of safety but also had not nurtured basic attitudes and habits of prudent behaviour.

\section{Discussion}

This study used a mixed methods research design in order to combine quantitative surveys with qualitative interviews to generate a well-rounded picture of the perceptions of teachers about safety in general and the unsafe practices of teachers and other staff in school laboratories in Saudi Arabia. Regardless of the small sample size, the results of this study are important as all survey questions were consistently rated by the respondents. All participants could also relate to the interview questions.

From the survey data it is evident that the teachers had only a baseline knowledge and lacked awareness of chemical symbols and signs as well as appropriate chemical storage practices. Knowledge of the signs would have enabled the staff to avoid the hazard. Qualitative data corroborates questionnaire data as the interview data had identified multiple instances when teachers and other staff were unable to manage health and safety issues in school due to lack of knowledge, training and also because the policymakers were not genuinely committed to continuous improvement in health and safety in school laboratories.

One of the findings was the absence of appropriate safety training programmes for teachers. In regard to other safety procedural measures, a major concern was the way in which school staff were acquiring information and disposing chemicals. This is consistent with literature which suggests that teachers without training rely on their own beliefs and general knowledge to minimize safety and health risks (Chumbley 2015). Results show that training can attain objectives such as increased knowledge of hazard awareness and adoption of safe work practices. This is congruent with literature which provided evidence that changing the attitude and behaviour of staff through training can help recognise hazards and prevent injuries (Lavack et al. 2008; Power and Baqee 2010).

The findings indicate that if a culture of safety has to be created in school laboratories, there should be sound policies as well as comprehensive training programmes for school staff. This is congruent with literature that leadership and training, as well as consistent evaluation are vital for creating a safety culture in educational institutions (National Research Council 2011; Wamuziri 2011; Finster 2017).

From this study some implications for policy concerning health and safety in school laboratories are evident: 


\section{EDUCATION}

- $\quad$ There is a need for adequate training so that schools can develop a safety culture which can provide new avenues for improving health and safety in schools.

- $\quad$ There is the need for a higher level of participation by all school staff.

- $\quad$ Policy makers should develop a clear strategy for monitoring and supporting health and safety, with suitable mechanisms for evaluating the actions of school staff.

The findings of this study provide directions for further development and research.

\section{Limitations and conclusion}

This research study was limited to 19 secondary school in 2 cities in Saudi Arabia. The quantitative phase involved administering questionnaires to 147 teachers, which was a relatively small sample Although the sample and the area covered was small, the results revealed that the concept of safety culture has not gained much recognition within the schools that were investigated as part of this study. Although this project has yielded relatively rich data, caution should be exercised in interpreting these results. Further exploration using Analytic Hierarchy Process (AHP) survey can determine the importance of the barriers and challenges facing school staff and laboratory technicians and to rank them priority wise. Results from such an analysis could help school management and policymakers to make better decisions.

\section{Acknowledgements}

The author was solely responsible for the design, analysis, and interpretation of the findings. I gratefully acknowledge all those who volunteered as participants in the study.

\section{Funding}

This research did not receive any specific grant from funding agencies in the public, commercial, or not-for-profit sectors. 


\section{References}

Adane, L., and A. Abeje. 2012. "Assessment of Familiarity and Understanding of Chemical Hazard Warning Signs among University Students Majoring Chemistry and Biology: A Case Study at Jimma University, Soutwestern Ethiopia." World Applied Sciences Journal, 16(2): 290-299.

Alsubaie, A.S.R. 2017. "School Safety and Emergency Preparedness in Saudi Arabia: A Call for Effective Action." International Journal of Research in Medical Sciences 5(4) dx.doi.org/10.18203/2320-6012.ijrms20171221

Alsubiaee, K.M., M. Alshahrani, A.B. Alazmi, and R.A. Alsadoon. 2017. "Implementation of Safety Standards in Saudi Arabian Scientific Laboratories: An Empirical Study." Journal of Arthritis 6: 249. dx.doi.org/10.4172/2167-7921.1000249

Alsubie, F.N., S. lbedour, J. Augusto, G, Reed, and J. Merrick. 2017. "School Safety Challenges and School Crisis in Saudi Arabia." International Journal of Child and Adolescent Health 10(3): 112-124.

Alyammahi, A. 2015. "The Current Status of Safety in High School Chemical Laboratories in Kentucky." Online Theses and Dissertations. 331. Eastern Kentucky University.

Ansa, M., M. Bibisio, B. Kuma, and K. Osuman. 2016. "Investigation of Laboratory and Chemical Safety in Wolaita Sodo University, Ethiopia." Chemistry and Materials Research 8(11): 23-33.

Bahram, S. S., S. Maryam, and M.S. Fatemeh. 2013. "A Survey on the Pre-Service Chemistry Teachers' Lab Safety Education." Procedia - Social and Behavioral Sciences 90: $57-62$.

Bekhet, A.K., and J.A. Zauszniewski. 2012. "Methodological Triangulation: An Approach to Understanding Ddata." Nurse Researcher 20(2): 40-43. doi.org/10.7748/nr2012.11.20.2.40.c9442

Braun, V., and V. Clarke. 2006. "Using Thematic Analysis in Psychology." Qualitative Research in Psychology, 3(2): 77-101.

Chumbley, S. B. 2015. "Laboratory Safety Practices of New Mexico Agricultural Science Teachers." Journal of Agricultural Systems, Technology, and Management, 26: 1-13.

Creswell, J.W. 2013. Research Design: Qualitative, Quantitative, and Mixed Methods Approaches. Thousand Oaks, CA: Sage.

Driscoll, D.L. 2011. "Introduction to Primary Research: Observations, Surveys, and Interviews." In Writing spaces: Readings on writing, edited by C.L. Lowe and P. Zemliansky, 153-174. San Francisco, CA: Parlor Press. 
Education Bureau. 2013. "Safety in Science Laboratories." Accessed October 302018. http://cd1.edb.hkedcity.net/cd/science/laboratory/safety/SafetyHandbook2013_English.p df

American Chemical Society. 2012. Creating Safety Cultures in Academic Institutions: A Report of the Safety Culture Task Force of the ACS Committee on Chemical Safety, Washington D.C: American Chemical Society.

Finster, D, C. 2017. Safety in Academic Chemistry Laboratories 8th ed. Washington D.C: American Chemical Society.

Högström, P., C. Ottander, and S. Benckert. 2010. "Lab work and Learning in Secondary School Chemistry: The Importance of Teacher and Student Interaction." Research in Science Education, 40: 505-523.

Ijaz, S., and N. Malik. 2018. "Chemical Safety: Knowledge, Attitude and Practices of Science." Paper presented at the Teachers International Conference - New Perspectives in Science Education, Florence, Italy, 22 - 23 March 2018.

Ismail. Z. S., A. Kadir, and K. Aiyub. 2015. "Promoting OSHA at Higher Institutions: Assessment of Level of Safety Awareness among Laboratory Users." Taylor's Business Review, 5(2): 155-164.

Langerman, N. 2009. "Laboratory Safety." Journal of Chemical Health and Safety, 6(3): 49-50.

Lavack, A.M., S.L. Magnuson, S. Deshpande, D.Z. Basil, M.D. Basil, and J.H. Mintz. 2008. "Enhancing Occupational Health and Ssafety in Young Workers: The Role of Social Marketing." International Journal of Nonprofit and Voluntary Sector Marketing, 3(3): 193-204.

Mallonee, S., C. Fowler, and G. R. Istre. 2006. "Bridging the Gap between Research and Practice: A Continuing Challenge.” Injury Prevention, 12(6): 357-359.

Mason, M. 2010. "Sample Size and Saturation in PhD Studies using Qualitative Interviews." Forum Qualitative Sozialforschung/Forum: Qualitative Social Research, 11(3): Art. 8. Accessed September 3 2018. http://nbn-resolving.de/urn:nbn:de:0114fqs100387

Miliszewska, I., and E. Sztendur. 2011. "Playing it Safe: Approaching Science Safety Awareness through Computer Game-Based Training." Issues in Informing Science and Information Technology, 8:37-47.

Morgan, D. L. 2014. Integrating Qualitative and Quantitative Methods: A Pragmatic Approach. London: Sage. 


\section{EDUCATION}

National Research Council. 2011. Prudent Practices in the Laboratory: Handling and Management of Chemical Hazards, Washington, DC: The National Academies Press. doi.org/10.17226/12654.

Power, N., and S. Baqee. 2010. "Constructing a 'Culture of Safety': An Examination of the Assumptions Embedded in Occupational Safety and Health Curricula delivered to High School Students and Fish Harvesters in Newfoundland and Labrador." Canada Policy Practice Health and Safety, 8 (1): 5-23.

Saunders, M., P. Lewis, and A. Thornhill. 2009. Research Methods for Business Students. 4th edn. Essex: Person Education

Silverman, D. 2006. Interpreting Qualitative Data: Methods for Analysing Talk, Text and Interaction. 3rd ed. London: Sage.

Streiner, D.L., and G.R. Norman. 2008. Health Measurement Scales: A Practical Guide to their Development and Use. 4th ed. Oxford: Oxford University Press.

Taatila, V., and K. Raij. 2012. "Philosophical Review of Pragmatism as a Basis for Learning by Developing Pedagogy." Educational Philosophy and Theory, 44(8): 831844.

Wamuziri, S. 2011. "Factors that Contribute to Positive and Negative Health and Safety Cultures in Construction." Paper presented at the CIB W099 Conference on PreventionMeans to the End of Construction Injuries, Illnesses and Fatalities, CIB: Rotterdam. 